RUNNING HEAD: Self-Reports of Habit

Publisher: Taylor \& Francis

Journal: Health Psychology Review

DOI: http://dx.doi.org/10.1080/17437199.2014.959728

\title{
The Subjective Experience of Habit Captured by Self-Report Indexes May Lead to Inaccuracies in the Measurement of Habitual Action
}

\author{
Martin S. Hagger \\ Curtin University, Australia \\ Amanda L. Rebar \\ Central Queensland University, Australia \\ Barbara Mullan, Ottmar V. Lipp \& Nikos L. D. Chatzisarantis
}

Acknowledgements and notes

Commentary on Gardner, B. (2014). A review and analysis of the use of 'habit' in understanding, predicting and influencing health-related behaviour. Health Psychology Review, Advance online publication. doi: 10.1080/17437199.2013.876238

The contribution of the lead authors, Martin S. Hagger and Amanda Rebar, was supported by grants from the Health Collaborative Research Network.

Peer review and processing of this article was handled by acting Associate Editor, Professor Paul Norman, independent of the current Editor-in-Chief, Associate Editors and Editorial Board of Health Psychology Review.

Martin S. Hagger, Barbara Mullan, Ottmar V. Lipp and Nikos L. D. Chatzisarantis, Laboratory of Self-Regulation, Health Psychology and Behavioural Medicine Research Group, School of Psychology and Speech Pathology, Faculty of Health Sciences, Curtin 
University, Perth, WA, Australia; Amanda Rebar, Centre for Physical Activity Studies, Institute of Health and Social Science Research, Central Queensland University, Rockhampton, Queensland, Australia.

Correspondence concerning this article should be addressed to Martin S. Hagger, Laboratory of Self-Regulation, Health Psychology and Behavioural Medicine Research Group, School of Psychology and Speech Pathology, Faculty of Health Sciences, Curtin University, GPO Box U1987, Perth, WA 6845, Australia, email: martin.hagger@ curtin.edu.au 
The habit construct, and proxy measures of habit such as frequency and recency measures of past behaviour (Bagozzi \& Warshaw, 1990), has been a topic of considerable interest to health psychology theorists and researchers interested in the factors related to health behaviour (Ajzen, 2002; Chatzisarantis, Hagger, \& Smith, 2007; Hagger, Anderson, Kyriakaki, \& Darkings, 2007; Hagger, Chatzisarantis, \& Biddle, 2001; Hagger, Chatzisarantis, \& Harris, 2006; Norman \& Conner, 2006; Norman, Conner, \& Bell, 2000; Ouellette \& Wood, 1998; Verplanken \& Faes, 1999). Gardner (2014) recently reviewed the literature on the effects of the habit construct in health-related research. In the review, habit was defined as a "as a process by which a stimulus automatically generates an impulse towards action, based on learned stimulus-response associations" (p. 4). Gardner's review represents a step forward in understanding the various definitions of habit in the social psychological literature applied to health, and provides considerable insight into the definitions of habit, types of habitual behaviour, effectiveness of previous models and tests of habit in the health-related literature, the limitations of habit research, avenues for future research, and implications for interventions.

One topic on which Gardner focuses is the various means by which habit has been measured in previous research. He indicates that self-report habit indexes, in which individuals reflect on the automaticity of action through their previous experience, represent the typical means to measure habit (Gardner, Abraham, Lally, \& de Bruijn, 2012; Verplanken \& Orbell, 2003). Gardner touches upon some of the limitations of such measures, indicating that the measures neglect cues (Sniehotta \& Presseau, 2012) and that some of the items likely invite responses consistent with frequency of action rather than automaticity (Gardner \& Tang, 2014). In this commentary, we aim to contribute to, and extend, Gardner's points on the limitations of habit measures. We contend that such measures do not solely capture habitual cues to behaviour or habitual action. Furthermore, we claim that the measures are 
problematic in that individuals are unlikely to have access or awareness of the cues and associated responses that give rise to habitual action. Reliance on such indexes may lead to erroneous inferences in the extent to which behaviours are controlled by habitual processes. We illustrate our points with examples from the health behaviour context.

We wholly endorse Gardner's definition of habitually-initiated behaviour through his synthesis of research and theory on habit. We also agree that habitually-initiated behaviour should be distinct from habitually-performed behaviours. Gardner makes it clear that a distinction needs to be made between learned cue-induced triggers to action, which may be habitual, and the subsequent chain of actions and behavioural responses that require considerable planning and deliberative processing (c.f. Hagger, 2013, in press; Hagger \& Chatzisarantis, 2014; Hagger \& Luszczynska, 2014; Hofmann, Friese, \& Wiers, 2011; Sheeran, Gollwitzer, \& Bargh, 2013; Strack \& Deutsch, 2004). Events in the environment may trigger thoughts of an intended behaviour that are activated automatically, but the processes that lead to enacting that behaviour require considerable planning and, possibly, flexibility of thought. For example, a smoker may have strong social cues to smoke after eating a meal at a restaurant, but if she is in a non-smoking venue or has run out of cigarettes, she will have to plan to discover the best place to smoke or locate a vendor for cigarettes. Of course, some of the actions along the way of enactment may be habitually-performed, such as the decision itself of the need to buy cigarettes, but we suspect that very few of the actions that constitute behaviour in this example are truly habitual. Health behaviours are, on the whole, extremely complex, as acknowledged by Gardner and colleagues (2014; Gardner, de Bruijn, \& Lally, 2012; Lally \& Gardner, 2013) and others (Lally, van Jaarsveld, Potts, \& Wardle, 2010; Maddux, 1997), such that the possibility of these behaviours being largely, or even partly, performed habitually may be quite unlikely. 
Individuals are, therefore, likely to be aware of many or all of the processes and experiences of engaging in a health-related behaviour. As Gardner (2014) contends: "The notion that everyday health behaviours may be wholly rigidly automated and performed with little control, awareness or intention does not match the subjective experience of most health behaviours" (p. 5). Habitual action is likely to have a substantive conscious component or be subject to conscious experience of the action by the individual. We contend that this creates a problem for self-report habit indexes, for conceptual and empirical reasons. Conceptually, individuals may not have access to the 'higher-order' cognitive processes that guide automatic or habitual behaviours. This has been documented in the literature on numerous occasions (Newell \& Shanks, 2014; Nisbett \& Wilson, 1977). For example, Nisbett and Wilson (1977), in their seminal review of introspective accounts and higher-order cognitive processes, indicate that individuals are unlikely to have access to the perceptual and memorybased processes that lead to many responses that occur at the implicit level. They review evidence that individuals are often unable to (a) identify key stimuli or cues that lead to responses, (b) identify whether or not a response to the cue has occurred, or (c) make any inferential link between a response and the critical cue. Habitual actions, by definition, are likely to share many of the components of the higher-order cognitive processes to which Nisbett and Wilson refer. This presents a problem for any self-report measure that purports to tap into processes likely to be of limited or no access to the respondent. Empirically, this also presents a problem for the validation of self-report measures of habit - what are they actually measuring? Given that the processes leading to habitual action are possibility 'out of reach' of the individual, the likelihood is that these indexes merely tap the experience of habit rather than actual habitual processes that lead to the action.

The likely lack of access by individuals to the executive processes that lead to habitual action means that reliance on self-report habit indexes may lead to inaccurate inferences as to 
the mechanisms that control action. Although individuals may be aware of their actions and subjectively feel that the action is controlled by automatic, non-conscious processes, it does not mean the action will actually be controlled by these processes. Furthermore, some of the apparently habitual actions that constitute health behaviour may be blended with other nonhabitual automatic processes (e.g., motivational, evaluative, or cognitive biases; Bargh \& Ferguson, 2000; Rothman, Sheeran, \& Wood, 2009). People may not, therefore, be able to distinguish between actions that are habitual and automatic, deliberative and conscious, or non-habitual and automatic. This will likely lead to confusion or inaccuracies by respondents over the attribution of their actions to habit.

Adopting a definition of habit as a behavioural response in a learned cue-response pairing, then, by definition, individuals would not have 'access' to the process that triggers a habitual behavioural response, as Nisbett and Wilson (1977) contend. As Gardner acknowledges, individuals may only be aware of the consequences of behavioural actions, and have access these consequences rather than the cue-induced initiation of the action at the time it was performed, which occurred without conscious awareness. For example, Gardner suggests that a smoker may be unaware of lighting up a cigarette but knows that they must have done so because the cigarette is alight (e.g., "I cannot recall lighting my cigarette, yet it is lit, so I must have lit it automatically"; Gardner, de Bruijn, et al., 2012; Sniehotta \& Presseau, 2012). However, we contend, that not being able to recall initiating an action or performing the action, does not, in itself, mean that the action was habitual. Memory research indicates that actions performed regularly become abstracted and normalised such that access to specific events and, therefore, recollection of those events, may be difficult (Repovs \& Baddeley, 2006). This is supported by evidence from the habit literature. Hyde et al. (2012) demonstrated that people with 'stronger' physical activity habits (higher scores on the physical activity self-report habit index) are worse at recalling their physical activity than 
people with weaker habits. However, that does not mean that the action was performed, at any stage, from initiation through performance to completion, through non-conscious or habitual processes. In other words, people's recollection as to whether a behaviour was initiated or performed automatically may be inherently unreliable as a measure of habit. To further illustrate this point, Gardner and Tang (2014) recently found that participants are likely to encounter a considerable number of difficulties recalling actions, cues to action, and the extent to which they are 'automated' when completing self-reported habit indexes.

Individuals may believe that a behaviour is habit driven and an action that they believe they do without conscious awareness or cognitive input, but that subjective experience may be inaccurate. Individuals may falsely attribute an action they do regularly to be 'habit', when, in reality, the behavioural response requires considerable cognitive effort and deliberative planning even if the initiation of the action itself may be a learned response to a cue or some event in their environment. Similarly, individuals may engage in behaviours that are a direct response to a cue or action but they may consider it an action over which they believe they have considerable control. If behaviours are initiated by automatic processes, the hallmark of habits, then there would be an expectation that people would have little access to the processes that led to their initiation or enactment, and, they may very well make erroneous judgements on self-report instruments that ask them to self-report the extent to which their behaviour is automatized (Nisbett \& Wilson, 1977).

The ready availability of measures that ostensibly tap 'automatic' or 'implicit' biases may provide opportunity to provide evidence for the concurrent validity of self-report habit indices (Nosek, Greenwald, \& Banaji, 2007). Correlating self-report habit indexes for health behaviours of interest with measures of implicit processes may provide some corroboration for the indexes. Confirming concurrent validity may be a boon to social scientists looking for a valid means to measure implicit or habitual processes in the field when the administration 
of decision tasks is impractical. Could a self-reported habit index with respect to a particular behaviour, such as diet or alcohol consumption, correlate with a decision task that ostensibly taps automatic bias toward the same behaviour, such as a go-no go task for food preference (e.g., Veling, Aarts, \& Stroebe, 2013) or implicit association test for alcohol identity (e.g., Caudwell \& Hagger, in press), respectively? Supposing such tests provide the requisite corroborating evidence with, for example, medium-to-large effect sizes, would that evidence alone provide definitive confirmatory support that such indexes tap the precise automatic processes involved in habitual action? The correlations may give an indication that selfassessment of habits share substantive variance with implicit biases with the key caveat relating to accessibility of automated, implicit processes (Nisbett \& Wilson, 1977). But correlating the two measures alone may not lead to an entirely satisfactory resolution given the validity of the tests against which the self-reported habit index may be compared has also been hotly debated (e.g., Blanton et al., 2009; Fiedler, Messner, \& Bluemke, 2006; Friese, Hofmann, \& Schmitt, 2009).

It is also important to note that there may also be other 'automatic' processes that drive behaviour that may be attributed to habits, because people report that they experience them as 'automated', but may not be habitual at all. As self-report habit indexes focus on habit and associated automated processes there is the underlying assumption that all behaviours experienced as automatic are habitual and not due to other automatic processes that are independent of learned cue-response pairings. Research has shown that individuals may evaluate and, consequently, have automatic biases toward stimuli with which they are unfamiliar and to which they have had no previous exposure or stored information. Such biases could not have been developed through experience or the result of previously learned responses to cues presented in the environment. In other words, some automatic responses are independent of past experience or exposure. For example, Duckworth and Bargh (2002) 
showed that people have automatic biases toward novel stimuli to which they had no previous experience or exposure. In terms of health behaviour, such novel stimuli may be manifested in health-compromising behaviours to which an individual has not previously been exposed, such as eating a novel food or experiencing a novel substance (e.g., trying an illegal drug). Self-reported habit indexes, therefore, may not account for different types of automatic processes that may affect health behaviour.

In conclusion, the problem facing much of research in the health behaviour literature on habits is that it relies on self-report indexes that characterize habit as a subjective experience of automaticity. This is at loggerheads with Gardner's (2014) and others' definitions of habit as actions that are well-learned behaviours that are initiated, or performed, without any conscious awareness (c.f., Nisbett \& Wilson, 1977). This inconsistency, coupled with the fact that people tend to forget, or have difficulty recalling, the circumstances that lead to their behaviour, means that habit indexes likely capture more than just habitual action. Measures that capture the implicit, automatized links between health-related stimuli and concomitant learned responses such as implicit association tests may offer potential solutions to habit measurement (Keatley, Clarke, \& Hagger, 2012, 2013). However, researchers considering association measures must be aware that their use comes with the important caveats that they may lack applicability and ecological validity in health research (Gardner, 2014) and have been criticized for their lack of external validity (Blanton, Jaccard, Christie, \& Gonzales, 2007; Blanton et al., 2009). 


\section{References}

Ajzen, I. (2002). Residual effects of past on later behavior: Habituation and reasoned action perspectives. Personality and Social Psychology Review, 6, 107-122. doi: 10.1207/S15327957PSPR0602_02

Bagozzi, R. P., \& Warshaw, P. R. (1990). Trying to consume. Journal of Consumer Research, 17, 127-140. doi: 0093-5301/91/1702-000250200

Bargh, J. A., \& Ferguson, M. J. (2000). Beyond behaviorism: On the automaticity of higher mental processes. Psychological Bulletin, 126, 925-945. doi: 10.1037/00332909.126.6.925

Blanton, H., Jaccard, J., Christie, C., \& Gonzales, P. M. (2007). Plausible assumptions, questionable assumptions and post hoc rationalizations: Will the real IAT, please stand up? Journal of Experimental Social Psychology, 43, 399-409. doi: 10.1016/j.jesp.2006.10.019

Blanton, H., Klick, J., Mitchell, G., Jaccard, J., Mellers, B., \& Tetlock, P. E. (2009). Strong claims and weak evidence: Reassessing the predictive validity of the IAT. Journal of Applied Psychology, 94, 567-582. doi: 10.1037/a0014665

Caudwell, K. M., \& Hagger, M. S. (in press). Pre-drinking and alcohol-related harm in undergraduates: The influence of explicit motives and implicit alcohol identity. Journal of Behavioral Medicine. doi: 10.1007/s10865-014-9573-6

Chatzisarantis, N. L. D., Hagger, M. S., \& Smith, B. (2007). Influences of perceived autonomy support on physical activity within the theory of planned behavior. European Journal of Social Psychology, 37, 934-954. doi: 10.1002/ejsp.407

Duckworth, K. L., Bargh, J. A., Garcia, M., \& Chaiken, S. (2002). The automatic evaluation of novel stimuli. Psychological Science, 13, 513-519. doi: 10.1111/1467-9280.00490

Fiedler, K., Messner, C., \& Bluemke, M. (2006). Unresolved problems with the "I", the "A", and the "T": A logical and psychometric critique of the Implicit Association Test (IAT). European Review of Social Psychology, 17, 74-147. doi: 10.1080/10463280600681248

Friese, M., Hofmann, W., \& Schmitt, M. (2009). When and why do implicit measures predict behaviour? Empirical evidence for the moderating role of opportunity, motivation, and process reliance. European Review of Social Psychology, 19, 285-338. doi: $10.1080 / 10463280802556958$

Gardner, B. (2014). A review and analysis of the use of 'habit' in understanding, predicting and influencing health-related behaviour. Health Psychology Review, Advance online publication. doi: 10.1080/17437199.2013.876238

Gardner, B., Abraham, C., Lally, P., \& de Bruijn, G.-J. (2012). Towards parsimony in habit measurement: Testing the convergent and predictive validity of an automaticity subscale of the Self-Report Habit Index. International Journal of Behavioral Nutrition and Physical Activity, 9, 102. doi: 10.1186/1479-5868-9-102

Gardner, B., de Bruijn, G.-J., \& Lally, P. (2012). Habit, identity, and repetitive action: A prospective study of binge-drinking in UK students. British Journal of Health Psychology, 17, 565-581. doi: 10.1111/j.2044-8287.2011.02056.x

Gardner, B., \& Tang, V. (2014). Reflecting on non-reflective action: An exploratory thinkaloud study of self-report habit measures. British Journal of Health Psychology, 19, 258-273. doi: 10.1111/bjhp.12060

Hagger, M. S. (2013). The multiple pathways by which self-control predicts behavior. Frontiers in Psychology, 4, 849. doi: 10.3389/fpsyg.2013.00849

Hagger, M. S. (in press). The multiple pathways by which trait self-control predicts health behavior. Annals of Behavioral Medicine. doi: 10.1007/s12160-014-9631-x 
Hagger, M. S., Anderson, M., Kyriakaki, M., \& Darkings, S. (2007). Aspects of identity and their influence on intentional behaviour: Comparing effects for three health behaviours. Personality and Individual Differences, 42, 355-367. doi: 10.1016/j.paid.2006.07.017

Hagger, M. S., \& Chatzisarantis, N. L. D. (2014). An integrated behavior-change model for physical activity. Exercise and Sport Sciences Reviews, 42, 62-69. doi: 10.1249/JES.0000000000000008

Hagger, M. S., Chatzisarantis, N. L. D., \& Biddle, S. J. H. (2001). The influence of selfefficacy and past behaviour on the physical activity intentions of young people. Journal of Sports Sciences, 19, 711-725. doi: 10.1080/02640410152475847

Hagger, M. S., Chatzisarantis, N. L. D., \& Harris, J. (2006). The process by which relative autonomous motivation affects intentional behavior: Comparing effects across dieting and exercise behaviors. Motivation and Emotion, 30, 306-320. doi: 10.1007/s11031006-9046-5

Hagger, M. S., \& Luszczynska, A. (2014). Implementation intention and action planning Interventions in health contexts: State of the research and proposals for the way forward. Applied Psychology: Health and Well-Being, 6, 1-47. doi: 10.1111/aphw.12017

Hofmann, W., Friese, M., \& Wiers, R. W. (2011). Impulsive processes in the self-regulation of health behaviour: Theoretical and methodological considerations in response to commentaries. Health Psychology Review, 5, 162-171. doi: 10.1080/17437199.2011.565593

Hyde, A. L., Elavsky, S., Doerksen, S. E., \& Conroy, D. E. (2012). Habit strength moderates the strength of within-person relations between weekly self-reported and objectivelyassessed physical activity. Psychology of Sport and Exercise, 13, 558-561. doi: 10.1016/j.psychsport.2012.03.003

Keatley, D. A., Clarke, D. D., \& Hagger, M. S. (2012). Investigating the predictive validity of implicit and explicit measures of motivation on condom use, physical activity, and healthy eating. Psychol, Health, 27, 550-569. doi: 10.1080/08870446.2011.605451

Keatley, D. A., Clarke, D. D., \& Hagger, M. S. (2013). The predictive validity of implicit measures of self-determined motivation across health-related behaviours. British Journal of Health Psychology, 18, 2-17. doi: 10.1111/j.2044-8287.2011.02063.x

Lally, P., \& Gardner, B. (2013). Promoting habit formation. Health Psychology Review, 7, S137-S158, doi: 10.1080/17437199.2011.603640

Lally, P., van Jaarsveld, C. H. M., Potts, H. W. W., \& Wardle, J. (2010). How are habits formed: Modelling habit formation in the real world. European Journal of Social Psychology, 40, 998-1009. doi: 10.1002/ejsp.674

Maddux, J. E. (1997). Habit, health and happiness. Journal of Sport and Exercise Psychology, 19, 331-346.

Newell, B. R., \& Shanks, D. R. (2014). Unconscious influences on decision making: A critical review. Behavioral and Brain Sciences, 37, 1-+. doi:

$10.1017 / \mathrm{s} 0140525 \times 12003214$

Nisbett, R. E., \& Wilson, T. D. (1977). Telling more than we can know: Verbal reports on mental processes. Psychological Review, 84, 231-259.

Norman, P., \& Conner, M. (2006). The theory of planned behaviour and binge drinking: Assessing the moderating role of past behaviour within the theory of planned behaviour. British Journal of Health Psychology, 11, 55-70. doi: $10.1348 / 135910705 X 43741$ 
Norman, P., Conner, M., \& Bell, R. (2000). The Theory of Planned Behaviour and exercise: Evidence for the moderating role of past behaviour. British Journal of Health Psychology, 5, 249-261. doi: 10.1348/135910700168892

Nosek, B. A., Greenwald, A. G., \& Banaji, M. R. (2007). The Implicit Association Test at age 7: A methodological and conceptual review. In J. A. Bargh (Ed.), Automatic processes in social thinking and behavior (pp. 265-292). New York: Psychology Press. doi:

Ouellette, J. A., \& Wood, W. (1998). Habit and intention in everyday life: The multiple processes by which past behavior predicts future behavior. Psychological Bulletin, 124, 54-74. doi: 10.1037//0033-2909.124.1.54

Repovs, G., \& Baddeley, A. (2006). The multi-component model of working memory: Explorations in experimental cognitive psychology. Neuroscience, 139, 5-21. doi: 10.1016/j.neuroscience.2005.12.061

Rothman, A. J., Sheeran, P., \& Wood, W. (2009). Reflective and automatic processes in the initiation and maintenance of dietary change. Annals of Behavioral Medicine, 38, 417. doi: 10.1007/s12160-009-9118-3

Sheeran, P., Gollwitzer, P. M., \& Bargh, J. A. (2013). Nonconscious Processes and Health. Health Psychology, 32, 460-473. doi: 10.1037/a0029203

Sniehotta, F. F., \& Presseau, J. (2012). The habitual use of the self-report habit index. Annals of Behavioral Medicine, 43, 139-140. doi: 10.1007/s12160-011-9305-x

Strack, F., \& Deutsch, R. (2004). Reflective and impulsive determinants of social behavior. Personality and Social Psychology Review, 8, 220-247. doi: 10.1207/s15327957pspr0803_1

Veling, H. P., Aarts, H., \& Stroebe, W. (2013). Stop signals decrease choices for palatable foods through decreased food evaluation. Frontiers in Psychology, 4, 875. doi: 10.3389/fpsyg.2013.00875

Verplanken, B., \& Faes, S. (1999). Good intentions, bad habits, and effects of forming implementation intentions on healthy eating. European Journal of Social Psychology, 29, 591-604. doi: 10.1002/(SICI)1099-0992(199908/09)29:5/6<591::AIDEJSP948>3.0.CO;2-H

Verplanken, B., \& Orbell, S. (2003). Reflections on past behavior: A self-report index of habit strength. Journal of Applied Social Psychology, 33, 1313-1330. doi: 10.1111/j.1559-1816.2003.tb01951.x 